\title{
Research on the Space Construction Characteristics of Traditional Settlement in Sanzhou Village
}

\author{
Lingyu $\mathrm{Gao}^{1, *}$ \\ ${ }^{1}$ Fuzhou University Xiamen Academy of Arts and Design, Xiamen, Fujian 361001, China \\ *Corresponding author. Email: 799351573@qq.com
}

\begin{abstract}
The formation of traditional settlements has a rich historical and cultural heritage and is a non-renewable cultural heritage. The complex formation motives of traditional settlements vividly reflect the production method and life style, social organization form and so on of local residents. The site selection of the village, the spatial form, and the street pattern all reflect the life and construction wisdom as well as aesthetic taste of the people at that time. Therefore, this article uses the settlement space of Sanzhou Village as the carrier and the extraction of element types as the method to explore the characteristics of the construction of various elements in the traditional settlements, re-examine the value of traditional settlements and summarize the value carrying of Sanzhou Village.
\end{abstract}

Keywords: Traditional settlement, Space construction, Sanzhou Village.

\section{INTRODUCTION}

In the process of formation, Sanzhou Village integrates diversified cultures, which mainly include post road culture, immigration culture, Hakka culture, etc.

First, it was influenced by immigration culture. Sanzhou was originally composed of people from 7 surnames of Chen, Cheng, Luo, Gu, Lin, Dong, and Pan, but later they all moved out of Sanzhou for various reasons. In the middle and late Tang Dynasty, the Wen family moved in, and the Dai family moved to Sanzhou from Jiangxi in the last years of Tang Dynasty. During the Ming Dynasty, the Huang family moved in. In the process, the Hakka sub-nation of Sanzhou gradually formed a stable and fixed residence. Looking back at the immigration culture of the settlements along the Tingjiang Channel, the official opening of the Tingjiang Channel during the Song Dynasty and the early Yuan Dynasty should be one of the main reasons for the large-scale migration of Hakka ancestors to the Tingjiang River Basin. [1] The population explosion caused the counties in this area to increase continuously. After the area of Tingzhou stabilized during the Song Dynasty, more immigrants from the north were accommodated. In the process of mutual struggle and integration with the aborigines and the local geographical environment, they not only passed on the advanced production method and life style in the north, but also absorbed the local traditional culture. The collision of diversified cultural forms promoted the birth of the Hakka sub-nation, and the composing form of the traditional settlements along the Tingjiang Channel changed accordingly.

Secondly, it was influenced by the post road culture. In ancient times, the internal market economy of the Tingjiang Channel was not developed. It mainly focused on transit trade, transporting local specialties from places like Southern Jiangxi and other places to ChaozhouShantou region and Southeast Asia markets through Tingjiang and Hanjiang roadways, and exchanged them for grain, piece goods, salt, etc. This phenomenon was at a stage of prosperity and development from the beginning of the Qing Dynasty to the beginning of the Republic of China. At this time, there were several or even dozens of shipping docks on the Tingjiang River and its six major tributaries. The saying "3,000 in the upper reaches and 800 in the lower reaches" was also produced during this period. [2] This also enabled the Sanzhou Village along the route to form a relatively stable mode of interflow of foreign commodities. From the initial traditional handicraft industry and agriculture as the economic base, Sanzhou gradually transformed into foreign 
commercial trade after the opening of the Tingjiang Channel. The economic base determines the superstructure. During the Ming and Qing Dynasties, Sanzhou Village not only benefited from the opening of the Tingjiang Channel to develop water transportation, but also became an important transportation hub on the border of Fujian, Guangdong and Jiangxi because it was located on the traffic artery of Tingzhou South Road, being known as the "Green Ribbon of the Maritime Silk Road - a Bright Pearl on the Tingjiang River". [3]

Finally, it was influenced by Hakka culture. During the Southern Song Dynasty, although many northern immigrants gathered in the urban areas of Tingzhou and Ganzhou, the spread of Central Plain Culture in the vast mountainous areas and villages of Tingzhou and Ganzhou was still very weak. But in the process of various integration work, the borders of Fujian, Jiangxi, and Guangdong, especially in Tingzhou and Ganzhou, were gestating a new sub-nation of Han — the Hakka sub-nation. [4] After the opening of the post road from Longxing to Chaozhou in the Yuan Dynasty, the communication between Fujian, Jiangxi and Guangdong gradually became more frequent, and the internal mountainous and rural areas also exchanged a lot. The northern immigrants gathering in the urban areas of Tingzhou and Ganzhou gradually penetrated therein, and the Sanzhou Hakka culture was gradually taking shape. The Hakka culture largely influenced the construction characteristics of the settlement space of Sanzhou.

\section{HISTORICAL ATTRIBUTES OF SANZHOU VILLAGE}

\subsection{Attributes of Official Road}

The Tingjiang Channel crossed the ancient Gutingzhou Mansion (now Longyan, Sanming, etc.) to the territory of Guangdong. The Channel flowed in from Dawubei Village, Anjie Town, Ninghua County. After exiting the Dragon Gate, it crossed Xinqiao, passed through the gate of the town, rivers and fields, surrounded Sanzhou, exited from Meixi Village of Zhuotian Town, and then returned to the county from Xiangdian Town, Wuping County, flowing southeast. Later, it exited from Yanggu Village, Xuancheng Town, entered Shanghang, passes through Fengshi (now Yongding District, Longyan City) from Shanghang, and finally merged into Hanjiang River from Sanhe Town, Meizhou, Guangdong. On the way, courier stations were added. It is 220 kilometers in total ("Figure 1"). [5]
Sanzhou Village is an important courier-station settlement along the Tingjiang Channel.

During the Tang and Song Dynasties, Tingzhou's external transportation was not developed. The internal traffic of Tingzhou extended from north to south to Changting and stopped abruptly. The main reason was that Tingzhou could not be connected with coastal transportation. Because the geographical environment of Tingzhou to the south was mostly characterized by high mountains and lofty hills as well as rugged mountain roads, the ancient Chinese transportation first served for politics and military affairs, and at that time there was no military and political demand for expanding to the south in Tingzhou, the development of transportation in Tingzhou was still in a semi-natural state. Among the four major rivers in Fujian Province, the Minjiang River, Jinjiang River and Jiulong River all enter the sea from the east, and all have sea gates. Only the Tingjiang River flows into the sea from the south, laying the prerequisite for the development of the Tingjiang Channel. It was not until the Yuan Dynasty that the Tingjiang Channel officially became a national post road. There were courier stations at various locations along the Tingjiang Channel at different times. Among them, Sanzhou was coiled on three sides by the Tingjiang River and served as a transit station for Changting, Wuping and Liancheng. Therefore, after the opening of the Tingjiang Channel in the Song Dynasty, it became an important commercial port of ancient Gutingzhou Mansion, which was used to transfer goods, grains, and commodities. In the Ming Dynasty, the Sanzhou Post was set up. "The Sanzhou Post was 60 li from Linting Post upwards and 60 li from Lanwu Post downward. Eight workers staying at the post and three workers passing official documents were set up." [6] It became one of the "Three Great Posts" of ancient Tingzhou Mansion.

\subsection{Attributes of Commerce and Trade}

"Yinjiang River joins Matan River after 10 li out of Changting County, meets with Nanxi River after another $50 \mathrm{li}$, and then merges with Datan River after another 25 li until Shanghang County." [7] Yinjiang is Tingshui and Changting River is Tingjiang. It is also recorded in the part of Shanghang that "Changting River meets with the water of six towns after arriving in Shanghang County until it reaches Chaozhou. From Tingzhou to Chaozhou, there are 500 dangerous shoals with 
submerged reefs all over, which are the channels for the transportation of Chao salt". [7] Its attributes of commerce and trade began to take shape. In the 3rd year of Duanping, the government cleared the river channel and opened the Tingjiang Channel to facilitate the transportation of official salt. The Tingjiang Channel also became the golden waterway for the salt and grain trades between Fujian, Jiangxi and Guangdong. During the Ming and Qing Dynasties, shipping on the Tingjiang River was prosperous. Courier stations along the route also became a commercial settlement space for the market town function. Sanzhou was just one day away from the Tingzhou Mansion (now Changting County) by water. The ancestors of Sanzhou relied on the Tingjiang waterway to develop shipping. The saying "The sails are constantly seen during the day and the masts are moored in rows at night" vividly reproduces the busy scene of the gathering of merchants and bulk shipments of Sanzhou in the past. [8] As an important node settlement space along the Tingjiang Channel, Sanzhou Village naturally needed foreign business and trade.

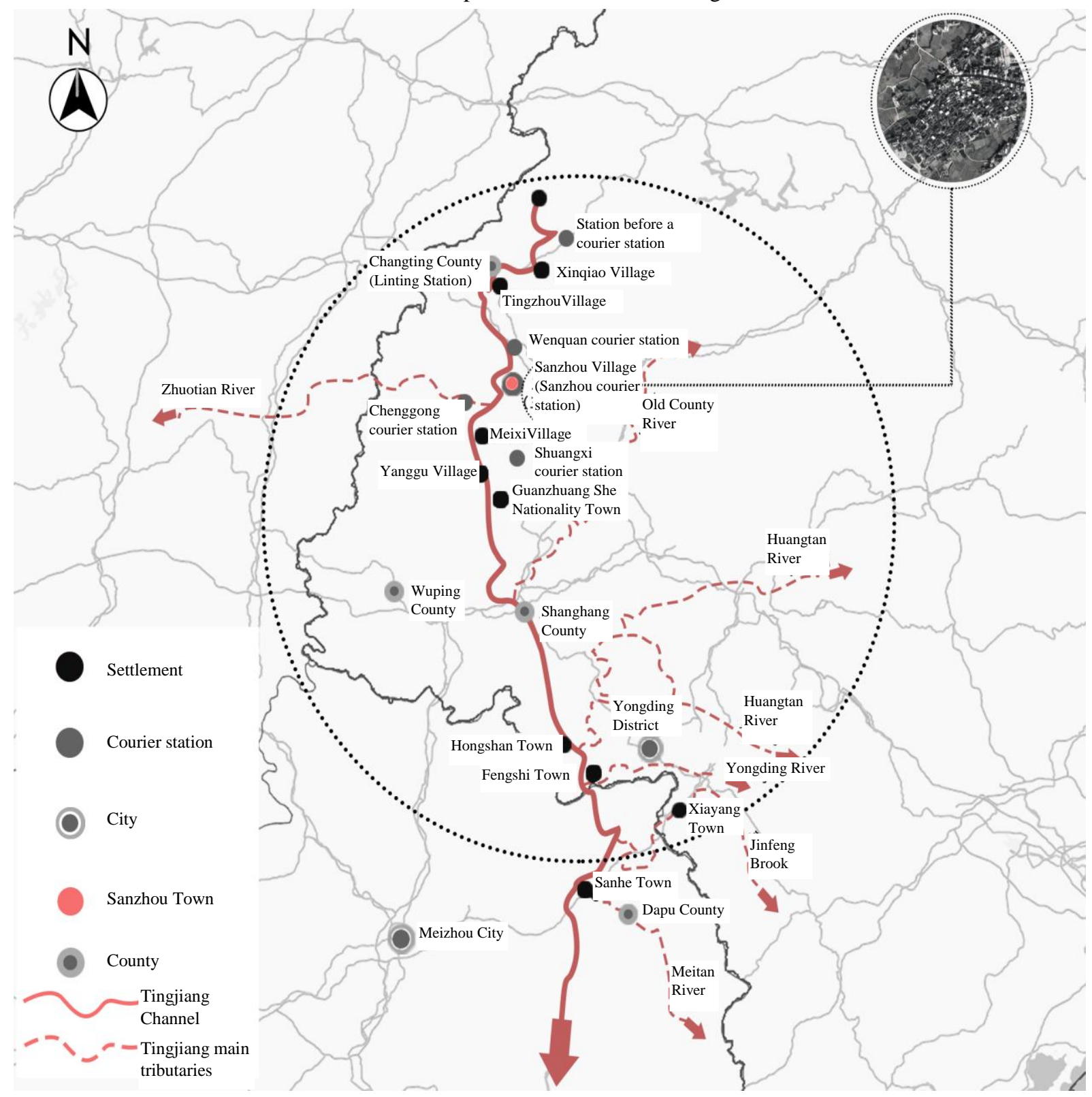

Figure 1 Tingjiang Channel and the distribution of traditional settlements along the route. (Source: The author's self-drawing based on Yan Guangwen's "The Opening of the New Post Road from Longxing to Chaozhou in the Yuan Dynasty and Its Impact on the Development of the Provincial Boundary of Jiangxi, Fujian, and Guangdong") 


\section{THE CONSTRUCTION CHARACTERISTICS OF SANZHOU VILLAGE}

According to Akira Fujii, the formation of the settlement space schema is divided into processes such as serialization, regionalization, and
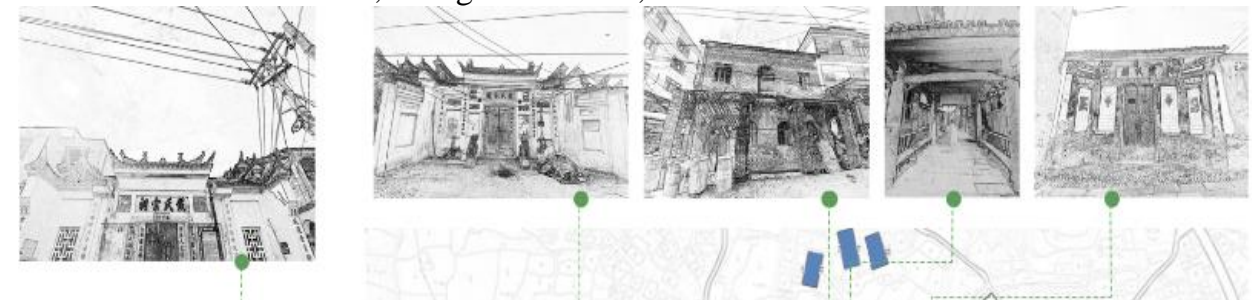

symbolization, however, the conception methods are not the same, but are split into numerous methods. [9] Due to the multi-type of conception methods, diversified settlement forms have been produced and the uniqueness of each settlement space has been promoted.

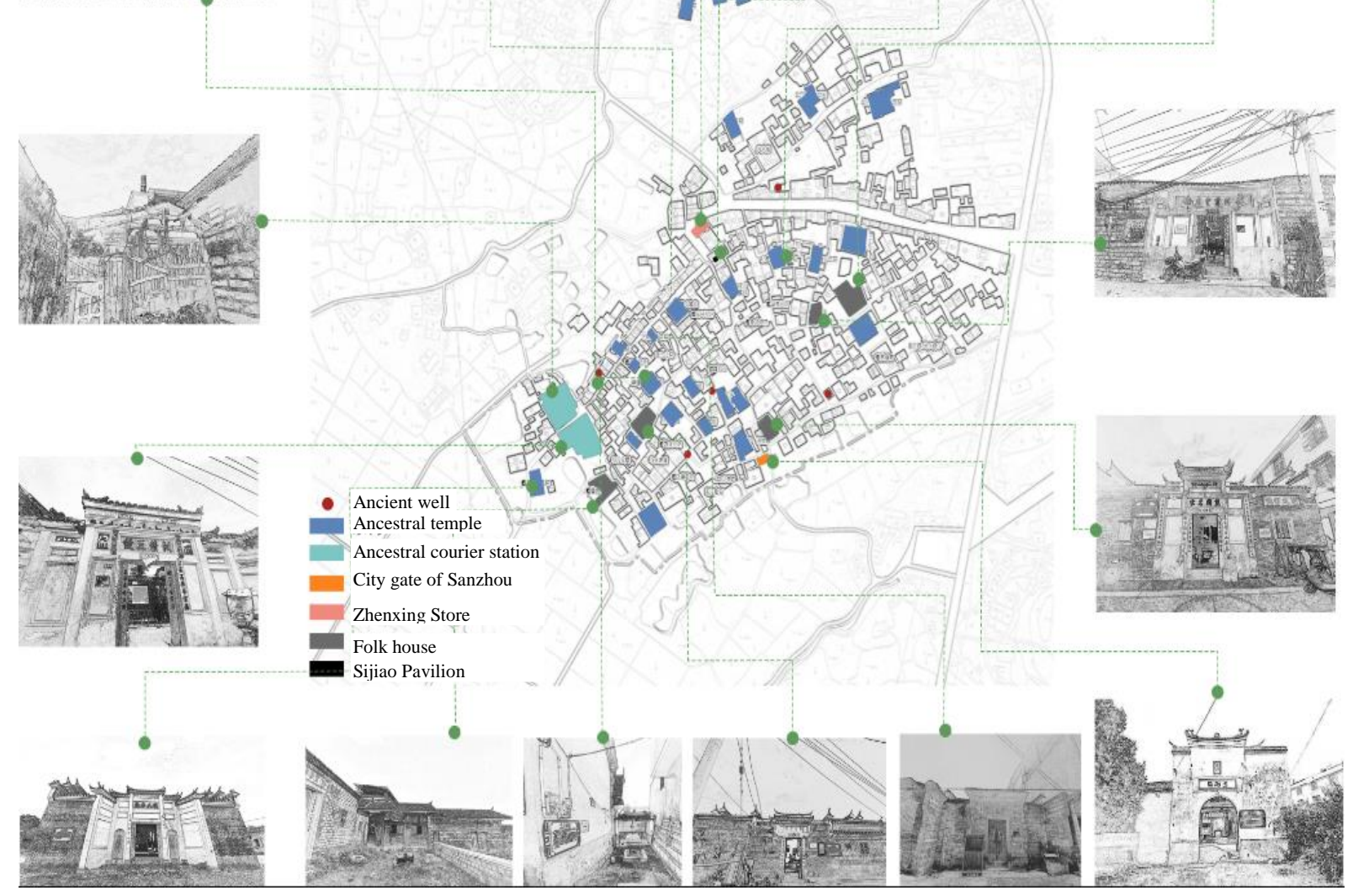

Figure 2 The overall spatial layout of Sanzhou Village (Source: Drawn by the author). 


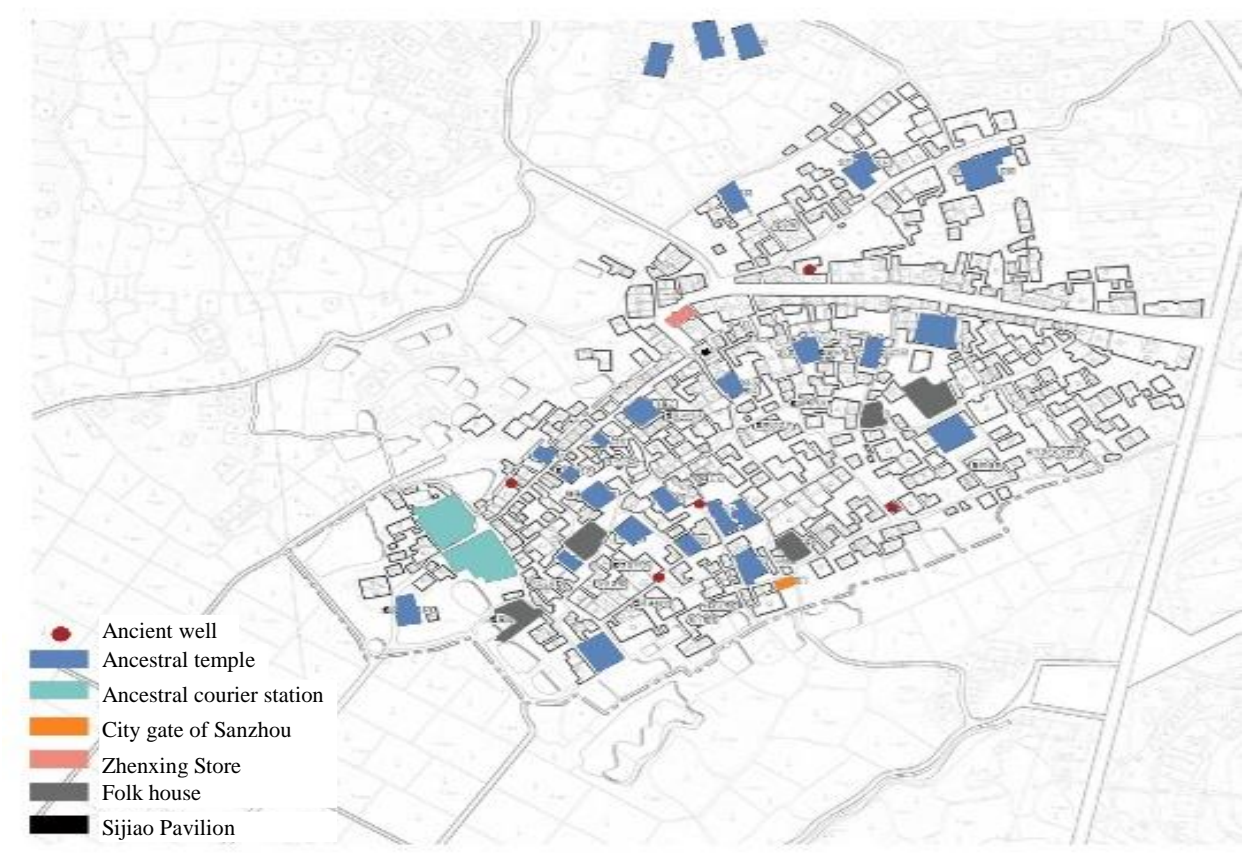

Figure 3 Distribution of important ancestral temples in Sanzhou Village (Source: Drawn by the author).

\subsection{The Spatial Layout of Sanzhou Village Construction}

The formation of settlement space has its own inherent spatial diagram. In the process of serialization of settlement space, Akira Fujii summed up two settlement space construction methods. The first is to clearly indicate the center: the settlement type is divided into two modes, unimodal and multimodal clusters. The second is to try to eliminate the center: (1) When there is no clear center in the settlement, measures need to be taken to paste and copy to expand the settlement in a certain same form of the residence; (2) The residence is distributed in scattered form in the settlement without a clear boundary .

During the Ming and Qing Dynasties, Sanzhou Village entered the prosperous period, and there were courier stations in the village. For convenience and efficiency, the locations of the courier stations were close to the dock, and were set on the periphery of the building area, close to Mingde Hall ("Figure 2"). The development of economy, population and transportation gradually saturated the Hakka culture of Sanzhou Village, thus forming the main gathering place of Hakkas. In Sanzhou Village with Hakka culture, blood relationship was the bond that maintained the patriarchal ritual system, forming a clan society where peope lived together as one clan based on blood relationship. Therefore, the traditional settlements of Sanzhou were formed on the basis of clan, and people's living together as one clan affected the building combination mode and settlement form. [10] Among them, the ancestral temple building was particularly important ("Figure $3 ")$. The internal layout of the space was arranged around the ancestral temple in an outward direction based on close or distant blood relationship. The closer to the ancestral temple dwelling, the stronger the kinship was, or to the outermost place, it intersected and merged with other surnames. [11] Therefore, in the construction process of the spatial layout of Sanzhou Village, there was a settlement multimodal cluster composed of multiple unimodal clusters, and this hierarchical structure fully embodied the concept of center and edge. The surnames of Wen, Yu, Qiu, and Dai who moved in first were in the relative center of the settlement. In this process, the population of Dai family multiplied quickly. According to "The Pedigree of Dai Family", the men of talent of descendants of the Dai family came out in succession in large numbers, and now the Dai family had the largest population in the settlement, reaching more than two-thirds. This also made the Dai the largest surname in the settlement, and its building cluster gradually squeezed into other surname clusters, and even penetrated into other surname clusters. The Huang family moved in during the Ming Dynasty, but at this time the cluster of Dai family had been 
firmly established, and the Huang family could only settle in the periphery, that was, to the north of the settlement. This kind of center-seeking structure aiming at gathering effect would result in a phenomenon, in other words, when encountering a group stronger than oneself, it would be squeezed or swallowed ("Figure 4"). Therefore, in a surname space in Sanzhou Village, ancestral temples of other surnames could always be seen. Clusters of great surnames were basically defined by streets, while clusters of small surnames were broken down or surrounded. In Sanzhou Village, the cluster form of mixed residence of mutiple surnames, just like "I was part of you and you were part of me", was established, which not only had a certain degree of compatibility, but also reflected the inevitable exclusivity of patriarchal blood settlements. The villagers had a strong collective sense and the dwellings were relatively compact. [11] From the perspective of the overall plane, Sanzhou Village is bounded by the Tingjiang River and the mountain massif. From the perspective of the construction area, the consanguineous boundary was particularly prominent, so the various surname clusters within the construction area were integrated with each other, but they were also independent of each other and had their own blood boundaries. During the Yuan Dynasty, shipping was developed. Shipping not only facilitated the production and life of the villagers, but also made thieves and bandits rampant. In order to defend against thieves and bandits, Dai Yingshou and the villagers connected the fire walls of various dwellings to cast the city wall to defend against them; in the spatial layout of Sanzhou Village, five ancient wells were set up according to the directions of the five elements; the ancient wells, city walls, city gates, and Dai Family Temple constituted the psychological boundary of the villagers in Sanzhou. ("Figure 4") From the perspective of the spatial plane form, the overall layout was clump-like. Inside the layout, the ancestral temple was the center to form the cluster, with a strong centrality. ("Figure 5") In the process of settlement construction, the spatial layout determined the skeleton of the settlement, which was an important link of the settlement road network structure.

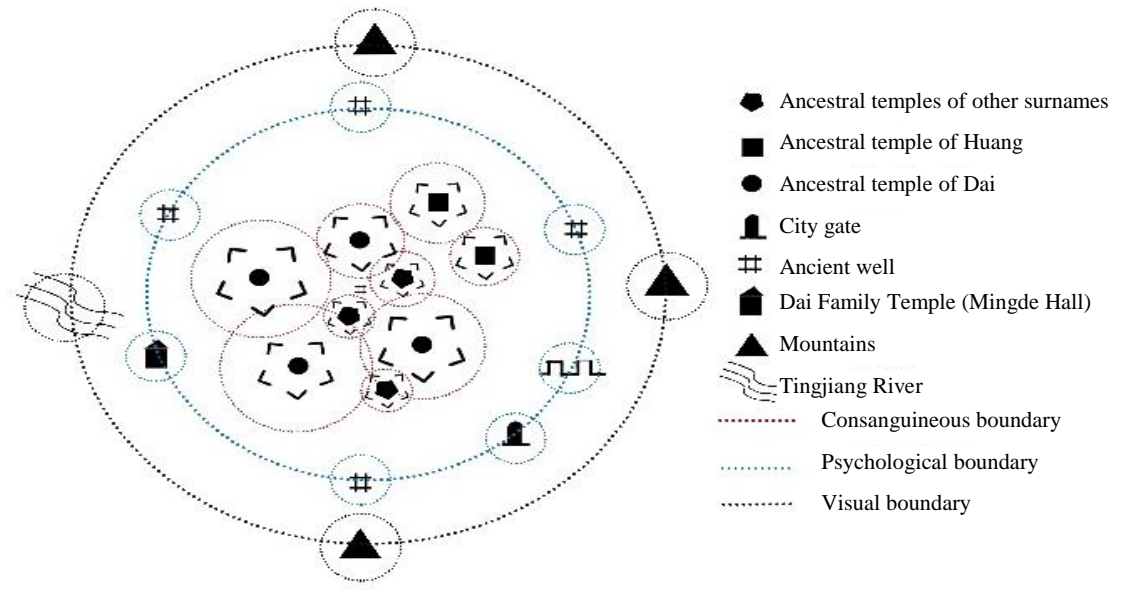

Figure 4 Schematic diagram of the boundary of Sanzhou Village (Data source: Drawn by the author).

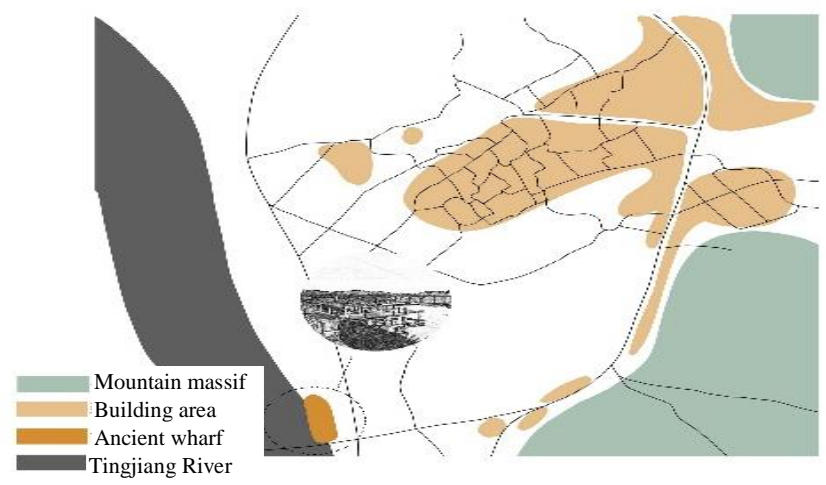

Figure 5 The spatial layout plane form of Sanzhou Village (Data source: Drawn by the author). 


\subsection{Road Network Structure Built in Sanzhou Village}

The road network structure is the skeleton in the settlement space, which connects the various elements in the settlement space in series, so that the settlement space exists as a whole. The Upper Street of Sanzhou Village separated the ancient village and the expanded village area on both sides of the arterial road. The alleys in the village were winding, especially in the ancient village area, there were a large number of ancient building groups. These ancient building groups relied on Tingjiang shipping to form a commercial and trade zone. With the economic base, the residents in the settlement became more active, and the ancestors of Sanzhou organized various trading activities. With a developed economy and frequent population mobility, the road network naturally expanded. Against the background of the previous article, Sanzhou Village formed an early market town model. The market town mainly surrounded the old street, and the old street was in the shape of a trisquare and was divided into Upper Street and Lower Street, with Zhenxing Store as a turning point. ("Figure 6") These streets were also the veins distinguishing clusters of different surnames in the settlement space. Walking from the Sijiao Pavilion from the northeast to the southwest, it was the Dai Family Temple in Sanzhou Village, also known as Mingde Hall. The Beimen Road to the north led directly to the cluster of Huang family. To the south of the old street mainly lived the Dai family, and there were more than a dozen Dai family ancestral temples. The south and east side were connected to the Lower Street in different directions with alleys such as Chengqiangkan Lane and Shangqian Road, leading to Libei Lane and Dongmen Road in the east. Among them, the structures of streets and lanes of Upper Street, Lower Street, Dongmen Road, Libei Lane, and Beimen Road were relatively regular. And the internal road network structure tended to bend as the building turns, flexibly interspersing in various building groups. The development of the linear arterial road demonstrated the cohesion of the villagers in Sanzhou, and people would gather the houses compactly to form an internal network structure, supporting the clump-like layout of Sanzhou Village in the spatial layout. ("Figure 7")

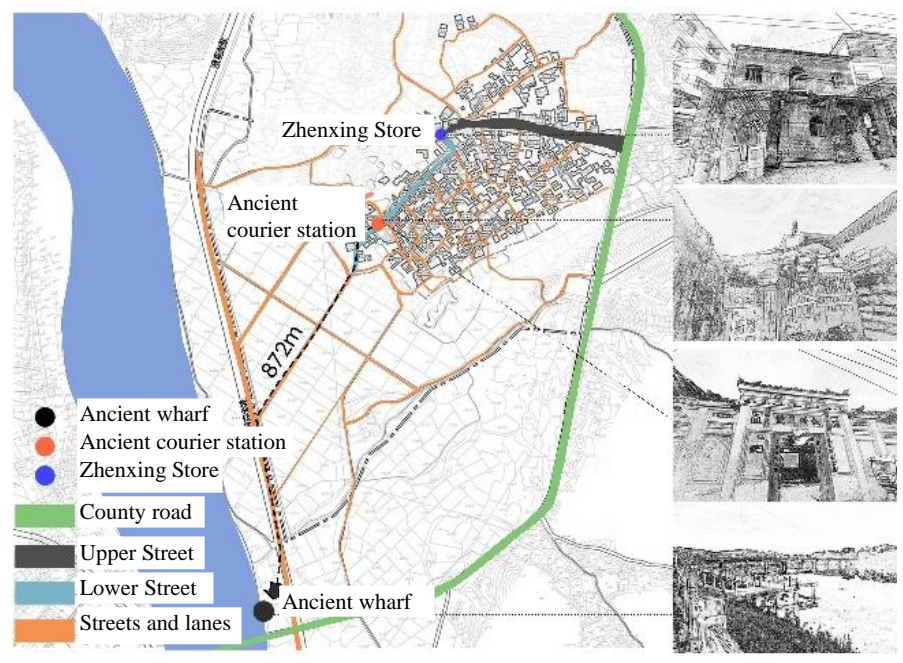

Figure 6 Road network structure in Sanzhou Village (Source: Drawn by the author). 


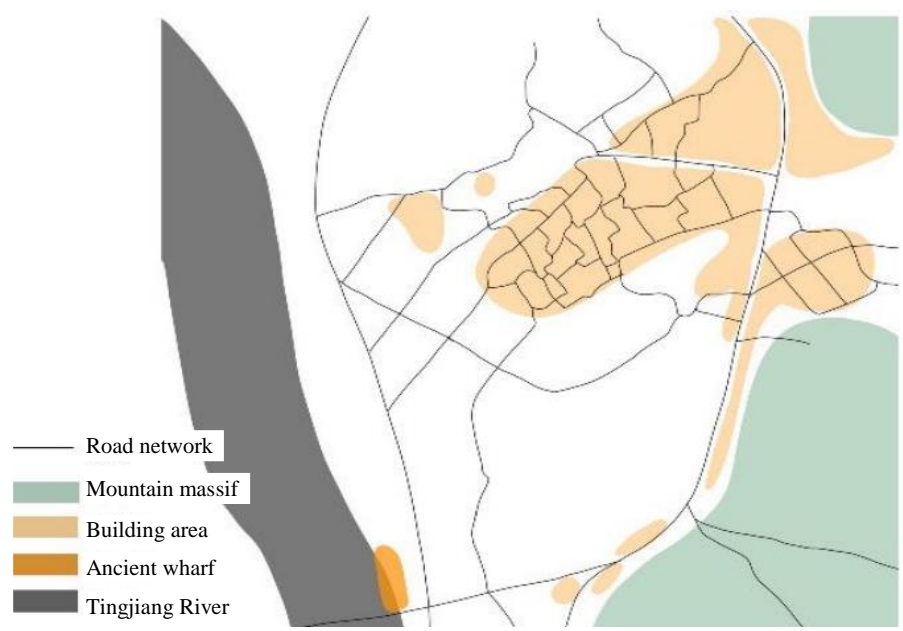

Figure 7 The plane form of the road network structure of Sanzhou Village (Source: Drawn by the author).

The road network structure of Sanzhou Village relied on the construction of the spatial layout, and the streets and lanes gradually formed a form suitable for the spatial layout along with the layout. If the spatial layout achieved the serialization of settlement construction, then the road network structure made the space regionalized. The periphery of anything would form a more or less scope of influence, that was, an area. In such an area, boundary was used to distinguish space from space. [9] The road network structure was the visible boundary distinguishing the internal area. The arterial road of Sanzhou Village distinguished a large number of ancient building groups from a new gathering place of villagers expanding on the other side. The reticular road network inside the settlement separated each building cluster. In the process of settlement construction, the road network structure must be very solid to support the overall spatial layout as a boundary for dividing areas. In the process of construction, if the historical background and cultural connotation of traditional settlement were to be symbolized into other elements in the area and displayed in people's vision, the most intuitive and common was the construction of buildings in the settlement.

\subsection{Construction Characteristics of Sanzhou Village Buildings}

Sanzhou Village was located along the Tingjiang Channel and was also a traditional Hakka blood-related settlement. Furthermore, it was in the humid and rainy natural environment of Western Fujian, and its architectural construction needed to adapt to the psychological needs of people's living together as one clan. Regardless of whether the ancestral temple or residential buildings, the hall was basically placed on the central axis as the core of the building, and the ancestral memorial tablet or the baldachine was placed in the center of the hall for worship. Due to clan beliefs, the ancients preferred to have a spacious and bright interior space when holding sacrificial activities, so they often reduced the construction of pillars, mainly reducing the use of pillars between the main hall and the corridors on both sides and the outer room of the main hall to create a bright and spacious atmosphere. The architectural prototype of this shape and structure is the "Sanhe Patio" and the traditional Jiugong pattern. Sanzhou Village is the traditional village with the most relics of such buildings. The construction of Sanzhou Village buildings can be summarized as the roof, spine, wall, gate tower and other salient features.

\subsubsection{Roof}

The roofs of buildings in Sanzhou Village are mostly overhanging gable roofs and flush gable roofs. These two types of roofs are similar in appearance, except that the flush gable roof is flush with the gable wall, and the purlin doesn't protrude beyond the gable wall, so the eaves are not jettingout on both sides of the gable wall, and the eaves and purlins on both sides of the overhanging gable roof extend out of the wall. [12] Therefore, most of the buildings of overhanging gable roofs are equipped with gable boards. Because Sanzhou Village is located in Western Fujian with frequent rains, in order to prevent rain, the ancients set up a gable higher than the roof at the junction of the rooftop and the wall crown, including Ma Tau Wall and Saddle-wall, as well as simple flush gable-style gable side, which were flush with the rooftop or 
higher than the rooftop. This not only enriches the layering of the building's façade, but also achieves the function of raining proof. The number of tiers of gable walls varies, and rich people's houses or ancestral temples will build multiple tiers of gable walls. For example, in the Dai Family Temple, the Ma Tau Walls on both sides of the entrance hall are two drop-out Ma Tau Walls and in the hall, they are three drop-out Ma Tau Walls, with rich layers; for another example, a reputable family of the Qiao State has the Ma Tau Wall in the first courtyard and the Saddle-wall in the second courtyard.

\subsubsection{Wall}

Sanzhou Village is roughly divided into two types of walling forms: rammed earth walls (The filling of rammed earth walls includes rubble, straw, brick rubble and ceramic fragments. The ceramic fragments are due to the establishment of a kiln in Sanzhou Village at one time) and blue brick walls. The base of the wall is made of three materials: concrete, pebble and blue brick. The interior wall is made of wooden planks. The more affluent families generally use wooden planks, while the Western Fujian is rich in cedar, so most people use the local cedar; or they may use bamboo woven with yellow mud, which is breathable and thin, and is heatinsulating and moisture-proof.

\subsubsection{Ridge}

The ridges of Sanzhou Village are compacted with tiles and bricks, and then fixed with dust removal. Within the village, it mainly has rakeangle ridges. People will make decorations on the ridge, which is called ridge decoration. The ridge decoration not only plays a beautifying role, but also protects the wood components at the ridge line from rain erosion. Its decorative image also expresses different auspicious meanings. [7] Sanzhou Village is mainly decorated with curling grass, Chiwen, swallowtail, cod fish and other decorations. Iron or copper wires are used to make this kind of abstract shape. In some special locations, for example, at a $\mathrm{T}$-junction, a ridge brake will be placed in the center of the main ridge to keep the house safe.

\subsubsection{Beam Column Construction}

Sanzhou's beam column construction is mainly composed of a combination of post and lintel construction and column and tie construction. As mentioned in the previous article, people in
Sanzhou Village like spacious space due to clan beliefs, and the post and lintel construction has more lintels and fewer pillars, which is easier to form a larger space and is mostly used in ancestral temples; while the column and tie construction is generally used in the second room of the building, and exquisite decorative patterns will be carved on the beam columns.

\subsubsection{Gate Tower}

Gate tower is an important part of people's first impression of architecture. Therefore, in Sanzhou, whether it is a residential building or an ancestral temple, villagers will generally try their best to construct the gate tower of a building. Generally, the gate towers of the ancestral temples are more exquisite, well-decorated, and decorated symmetrically. The beams, pillars, and squarecolumns on the door are made of red sandstone, and the pillars are carved with couplets. For instance, the red sandstone material used in the gate tower of the Dai Family Temple (Mingde Hall) has not been damaged and rebuilt since its construction. On both sides of the door lintel, plasterwork is always symmetrically distributed with fierce beast heads, meaning to suppress evil and pray for safety.

The clan etiquette of Sanzhou Village occupies a high position, and Sanzhou villagers symbolize their sense of awe of their ancestors. Therefore, there is a clear difference between the architecture of the folk house and the ancestral temple, which distinguishes the status of the ancestral temple within the settlement and highlights the lofty status of the "ancestors". The first is to talk about the ancestral temple. The opening of the Tingjiang Channel made the economy of the settlements along the route more prosperous, and many families had funds to build expensive buildings. When they had the financial capacity, the first thing that the Sanzhou residents who paid attention to their ancestors built was the family ancestral temple. There are a lot of ancestral temples in Sanzhou Village, with Dai family ancestral temple being the main one. There are two types of ancestral temples in the village: the pure ancestral temple and the ancestral temple and the folk house in one. The pure ancestral temple is only used to worship the ancestors, discuss important affairs within the clan, or serve as a gathering place for the clan when there are important activities. The ancestral temple and the folk house in one: The main building is used for worship, and the two sides are occupied by the clansmen of the immediate family of the owner. 
And the ridge decoration of the ancestral temple is of a wide selection of colors and designs. Most of the decorations such as curling grass and Chiwen mentioned in the previous article appear on the ancestral temple. Of course, it is not ruled out that these decorations will also appear on the folk houses built by the villagers with abundant funds. Gate tower is also one of the symbols that distinguish the two. Not only is the gate tower decorated with complicated decorations, some ancestral temples also display stone lions to show their lofty status, such as the Dai Family Temple next to the folk house of Dai Yuanzhen. Secondly, it talks about residential buildings. The walls of the buildings are mostly simple, and the less wealthy people mostly use rammed earth walls, while the more affluent people mostly use blue bricks to build the walls, or add rammed earth outside the blue bricks. The roofs are mostly simple flush gable roofs, the overall color is steel grey, and there are no complicated ridge decorations and gate towers. Finally, the courier stations are more special. There are two courier stations left in Sanzhou Village: Sixu Sanyou and Qutang Old House. Built in the late Qing Dynasty, the interior of Qutang Old House has collapsed and is now missing its former appearance, with only the crumbling gate tower remaining. Built in the Ming Dynasty, the interior of Sixu Sanyou is largely destroyed, leaving only the gate tower and gable. However, the façade is still relatively well preserved and its luxury can be seen vaguely. The main ridge of the gate tower is equipped with two opposing Chiwen and the head is decorated with various folk techniques such as plasterwork, colored drawing, painting and calligraphy, and relief. There are beast heads carved under the short pillars on both sides of the door lintel, and inside the frame beside the short pillars, it shows different character stories with the help of plasterwork. Its exquisite degree is no less than that of some ancestral temples, explaining the importance of the courier station at that time.

To sum up, the construction of Sanzhou Village is mainly divided into residential buildings and ancestral temples. There are obvious differences in decoration, color and structure. And as a building to receive merchants, officials, etc. on the Tingjiang Channel, the courier station also symbolizes the prosperity of Sanzhou Village and the Tingjiang Channel. Its construction has also received huge financial support and the attention of the ancestors of Sanzhou, so its construction is also exquisite.

\section{THE VALUE CARRYING OF SANZHOU VILLAGE}

The value of traditional settlements is reflected in all aspects of the settlement space. If the overall layout of the space is the flesh of the settlement and the road network is its skeleton, then the building is the blood of the settlement, and the cultural background formed by the construction of the entire settlement becomes its soul. The perfect combination of these four can form a unique traditional settlement space. The construction of settlements transforms its value significance from intangible value to tangible material. The loadbearing elements in Sanzhou Village include the geographical location, public space, architectural space, and architectural structure of Sanzhou Village. The layout of settlement space, road network and buildings become carriers.

The spatial layout of Sanzhou Village, as a product of post road culture and Hakka culture, carries historical value; in the road network structure, the various streets and lanes are connected in series, and the cohesion of the residents behind them bears the humanistic value; the architectural form is the product of people's views and values and is the most intuitive expression of the differences between settlements, carrying artistic value ("Figure 8"). The Sanzhou Village carries a wealth of values. For example, the restoration of the ancient wharf is used to show the prosperity of Sanzhou Village as an important commercial port at that time or the streets and lanes are used to more clearly plan the market town function of Sanzhou Village; the value-carrying methods such as shipping on the Tingjiang River, the site selection of the village that reflects the changes of immigrants, and the spatial structure of the patriarchal consanguinity can be fully utilized and visualized. 


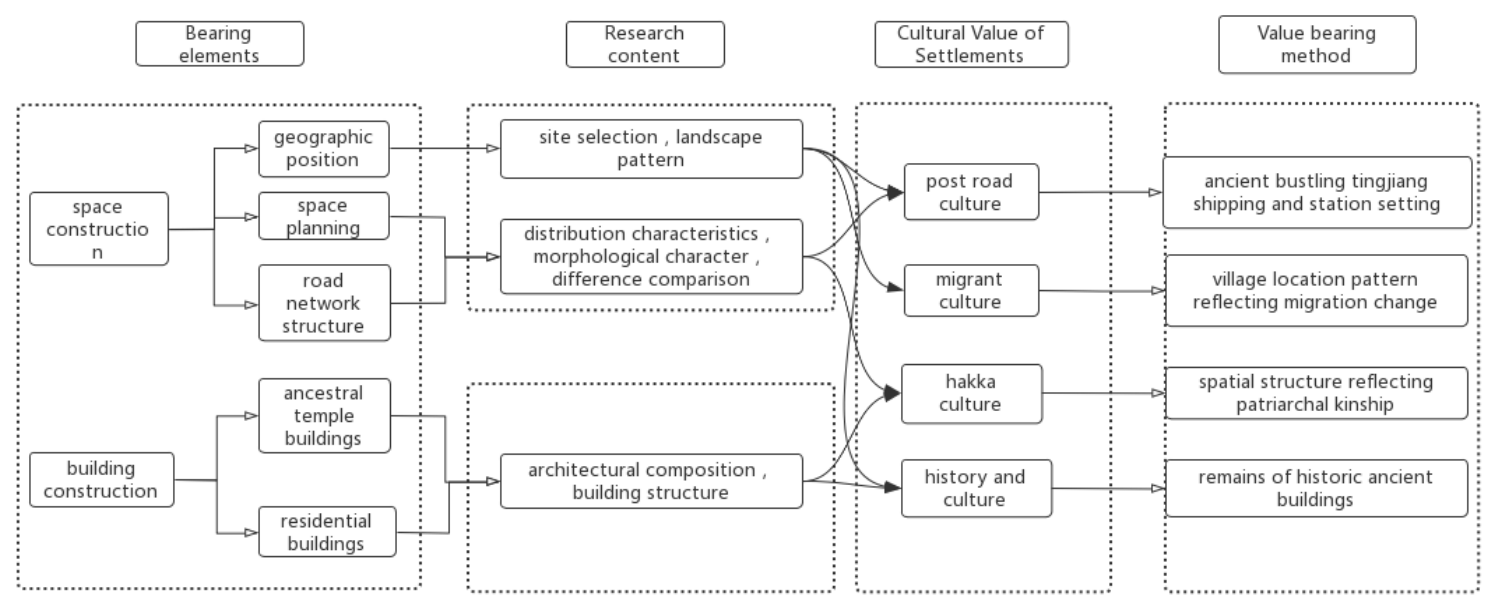

Figure 8 The Value Carrying of Sanzhou Village (Data source: Drawn by the author).

\section{CONCLUSION}

This article analyzes the construction characteristics of Sanzhou Village based on the settlement spatial layout, road network structure, and architectural characteristics, and summarizes the way it carries value. Its spatial layout reflects the construction characteristics of traditional Chinese consanguineous settlements, presenting a clear central space; as the skeleton of the settlement, the road network structure supports the expansion of the spatial layout of Sanzhou Village, presenting a regular mesh pattern; under the influence of the clan system and Tingjiang Channel, buildings have developed distinctly differentiated construction types, mainly the difference between the ancestral temple and the residential building. The prerequisite for a traditional settlement to become a community is that it must have individuality. Only by showing characteristics different from other settlement forms can it be recognized by the outside world. Therefore, there are no two identical settlements. Each settlement space is unique, even in the same natural conditions, historical background, etc. However, difference is the prerequisite for identity and the basis for the originality of the settlement. Therefore, the construction process of traditional settlements doesn't only follow a fixed spatial diagram, but is formed by social and customary norms triggered by different spatial contexts.

\section{AUTHORS' CONTRIBUTIONS}

This paper is independently completed by Lingyu Gao.

\section{REFERENCES}

[1] Zhang Zhengtian. The Relationship between the Change of Tingzhou Area and the Development of Tingjiang River Basin in the Period of Tang and Song Dynasties [J]. Tangshi Luncong, 2018(01):112-129. (in Chinese)

[2] Ge Wenqing. A Preliminary Study on the Evolution of the Export-oriented Hakka Economy in the Tingjiang River Basin [J]. JOURNAL OF LONGYAN TEACHERS COLLEGE, 1995(2): 40-47. (in Chinese)

[3] He Luke, $\mathrm{Yu}$ Fang. Analyses of the architectural and cultural characteristics of Sanzhou ancient village [J]. Shanxi Architecture, 2014, 40(011): 25-27. (in Chinese)

[4] Xie Chongguang. Social changes and new nation patterns in the border areas of Hunan, Jiangxi, Fujian and Guangdong in Song Dynasty [J]. Journal of Ningde Normal University (Philosophy and Social Sciences Edition), 2012(03):5-17. (in Chinese)

[5] Jin Yangchun. The regional development of Tingzhou and the formation of the Hakka subnation during the Song and Yuan dynasties [M]. China Social Sciences Press, 2015. (in Chinese)

[6] (Qing Dynasty) Revised by Hao Yulin et al. "The Records of Fujian Province" [Z]. Beijing Publishing House: Social Sciences Academic 
Press.Pishu Publishing Branch: 2018, Volume 16: 1218. (in Chinese)

[7] (Song Dynasty) Revised by $\mathrm{Hu}$ Taichu, Compiled by Zhao Yumu. "Lin Ting Zhi" [Z]. Fujian People's Publishing House: 1990. (in Chinese)

[8] Lai Shaoliang, Liu Kun. Ancient Hakka Village - Sanzhou [J]. CPPCC World, 2013(05): 61-63+66. (in Chinese)

[9] Akira Fujii. Exploring the settlement [M]. Ning Jing, trans. China Building Industry Press, 2003. (in Chinese)

[10] Wang Degen, Lv Qingyue, Wu Yongfa, Fan Ziqi. The characteristic of regional differentiation and impact mechanism of architecture style of traditional residence $[\mathrm{J}]$. Journal of Natural Resources, 2019,34(09):1864-1885. (in Chinese)

[11] Li Huazhen. Probing into the forms and characteristics of traditional settlement in Sanzhou and its contributing factors $[\mathrm{J}]$. Journal of Hebei University of Engineering (Social Science Edition), 2012, 29(04): 8890+113. (in Chinese)

[12] Su Wanxing. Jianming Gujianzhu Tujie [M]. Peking University Press, 2013. (in Chinese) 